\title{
全站仪实际应用于隧道断面测量中存在问题的探讨
}

\author{
邓庆珊
}

杭州铁安测绘有限责任公司

DOI:10.32629/gmsm.v2i6.398

[摘 要] 近些年来,随着城市轨道交通的快速发展,在建线路及运营线路越来越多, 同时在城市发展过程中,地铁沿线的新建项目增多, 对地铁隧 道结构安全要求也越来越高。这对地铁隧道结构监测而言都是严峻的考验, 因为地铁隧道结构监测贯穿始终。在地铁运营接管前需对地铁隧道 结构进行初始几何状态测量, 从而实现施工期与运营期隧道结构变形数据无㖓对接、权责的划分, 同时随着地铁保护相关法规的完善, 地铁周边 新建工程施工前也要求对地铁现状进行调查, 隧道断面测量都是不可或缺的一环。本文主要对全站仪应用于地铁盾构隧道断面测量中存在问题 的进行讨论和研究,旨在充分运用全站断面测量来提升地铁盾构隧道的安全性,为城市轨道交通保驾护航。

[关键词] 城市轨道交通; 全站仪; 断面测量; 地铁保护; 应用

城市轨道交通作为一个城市交通的大脉络, 在城市不断建设发展过程 中, 不可避免的对其产生影响, 为了规避或者减小这种影响, 各地市都相应 的建立起了地铁保护区。根据相关法律法规, 在地铁保护区范围内进行施 工作业就得对既有地铁线路进行保护区监测, 在施工前后都得对现有隧道 结构状态进行调查, 全站仪断面测量是对隧道结构几何尺寸的一个很好的 解决方案。全站仪断面测量是通过全站仪自带的隧道断面测量软件 (SimpleSection) 进行断面扫描采集数据, 选用隧道断面数据后处理软件 (Tunne1Monitor) 进行内业处理来实现隧道结构几何尺寸测量的。全站仪 在地铁隧道断面测量应用过程中, 为我们提供高精度结果以及高效率的同 时, 不可避免的也会遇到一些问题。

\section{1 问题的发现}

杭州地铁保护区内某区段内同时有两个地铁保护区监测项目, 两家地 铁保护监测单位按照相关要求对地铁区间盾构段隧道 300 环 200 环进行断 面测量, 隧道断面几何尺寸测量结果相差较大最大值达到 $22.8 \mathrm{~mm}$ 。为此, 地铁运营单位要求两家监测单位针对该部分测量结果进行复核。

根据运营单位要求, 两家监测单位对该部分进行了全站仪断面几何尺 寸测量复核, 复核时为了测量结果的可靠性, 400 环采用 $10 \mathrm{~cm}$ 步距进行扫描, 其他基本以 $20 \mathrm{~cm}$ 步距扫描。从复核结果来看, 两家单位断面测量结果差异 变小, 初步判断跟两家单位同时测量时采用的方法有关。具体隧道断面测 量结果对比见下表:

表1＼cjkstart两家监测单位隧道断面测量结果对比表

\begin{tabular}{|c|c|c|c|c|c|c|}
\hline \multirow{2}{*}{ 环号 } & \multicolumn{2}{|c|}{ 监测单位1 } & \multicolumn{2}{|c|}{ 监测单位 2} & $\begin{array}{c}\text { 首测差 } \\
\text { 值 }(\mathrm{mm})\end{array}$ & $\begin{array}{c}\text { 复测差 } \\
\text { 值 }(\mathrm{mm})\end{array}$ \\
\cline { 2 - 7 } & 首测值 $(\mathrm{mm})$ & $\begin{array}{c}\text { 复测值 } \\
(\mathrm{mm})\end{array}$ & $\begin{array}{c}\text { 首测值 } \\
(\mathrm{mm})\end{array}$ & $\begin{array}{c}\text { 复测值 } \\
(\mathrm{mm})\end{array}$ & & \\
\hline 300 & 36.6 & $/$ & 29.8 & 32.2 & -6.8 & $/$ \\
\hline 305 & 33.0 & 29.4 & 46.8 & 32.2 & 13.8 & 2.8 \\
\hline 310 & 33.6 & $/$ & 47.8 & 33.6 & 14.2 & $/$ \\
\hline 315 & 36.6 & $/$ & 32.8 & $/$ & -3.8 & $/$ \\
\hline 325 & 39.6 & $/$ & 41.2 & $/$ & 1.6 & $/$ \\
\hline 335 & 38.0 & 39.2 & 51.0 & 38.6 & 13.0 & -0.6 \\
\hline 345 & 43.4 & $/$ & 50.2 & $/$ & 6.8 & $/$ \\
\hline 355 & 45.6 & $/$ & 40.4 & $/$ & -5.2 & $/$ \\
\hline 375 & 41.2 & $/$ & 46.6 & $/$ & 5.4 & $/$ \\
\hline 385 & 38.0 & 38.2 & 43.2 & $/$ & 5.2 & $/$ \\
\hline 400 & 43.4 & 42.2 & 66.2 & 44.0 & 22.8 & 0.6 \\
\hline
\end{tabular}

\section{2 问题的分析}

通过两家监测单位隧道断面测量复核结果比对, 同时结合现场测量方 法及该段盾构段隧道状况, 分析误差较大主要原因分为三大类:

2. 1 现场扫描到的断面与实际盾构隧道轴线方向不垂直: 扫描断面处 于隧道转弯处、扫描断面隧道存在较大上下坡度及扫描断面管片存在较大 管片错台。

2. 2 数据后处理方法的不一致: 徕卡采用建立标准圆与实测椭圆对比, 人工剔除噪点、三维激光扫描仪采用建立的标准圆采用限差的方法自动剔 除噪点。

2.3 人为因素: 现场测量人员测测量知识水平及测量经验、数据处理 人员对现场的认识及测量方法的认知。

\section{3 解决的方法}

根据以上分析, 造成误差的三大原因, 数据处理方法及人为因素都 可以通过培训来解决。现场扫描到的断面与实际盾构隧道轴线方向不 垂直, 我们也可以通过统一测量方法来解决, 关键在于观测断面、测点 的布置。

通常情况下, 观测断面应选取在每一环管片的中间部位, 如有遮挡物 应尽量避开。断面初次测量时应当标识测站位置, 并在管片上标识断面测 量的定向点和后视点位置, 以保证每次测量时均在同一位置。

断面位置的确定可分为两类: 直线段和曲线段。

3. 1直线段: (1) 量取轨道中心点, 并做好标记; (2) 选取合适位置架设 全站仪使得全站仪中心在轨道中心点处整平; (3) 将激光点对准道床远处 且不小于 $20 \mathrm{~m}$, 在激光点对准位置附近量取轨道中心点, 调整全站仪, 使得 激光点对准本次量取的轨道中心点, 并记下全站仪水平角度; (4) 在上述记 录的水平角度加减 90 即可认为此时全站仪扫描到的断面基本与管片轴线 方向垂直, 此后确保全站仪水平角度不动; (5) 调整全站仪垂直角度, 使得 全站仪激光点分别对准靠近道床两边的管片上并做好标记。

3.2 曲线段: (1) 量取轨道中心点, 并做好标记; (2) 选取合适位置架设 全站仪使得全站仪中心在轨道中心点处整平; (3) 将激光点对准当前环管 片, 并使得目镜处于水平方向, 采用测距功能记录测量到的水平距离, 然 后调整全站仪水平角度后测距, 找出测得的最短距离时确保全站仪水平 角度不动, 此时认为全站仪扫得的断面基本与管片轴向方向垂直; 调整 全站仪垂直角度, 使得全站仪激光点分别对准靠近道床两边的管片上并 做好标记。

\section{4 解决的方法验证}

为了验证以上断面、点位选取方法的可靠性, 我们从以下两个不同角 
度对该方法进行了现场验证, 具体验证结果如下:

4. 1 根据上述方法, 选取某段隧道中一环进行了不同步距及对中方法 在直线段和曲线段进行了检核试验, 详细结果如下所示:

\begin{tabular}{|c|c|c|c|c|}
\hline 区段 & $\begin{array}{l}\text { 工 } \\
\text { 况 }\end{array}$ & 详情 & \begin{tabular}{|l|} 
最大径长变 \\
化量 $(\mathrm{mm})$
\end{tabular} & $\begin{array}{l}\text { 与工况 } 1 \\
\text { 差值 }(\mathrm{mm})\end{array}$ \\
\hline \multirow{6}{*}{ 直线段 } & 1 & 步距 $20 \mathrm{~cm}$, 远处对中, 距离钢尺测量对中 & 17.2 & / \\
\hline & 2 & 步距 $15 \mathrm{~cm}$, 平距对中 & 19. 6 & 2.4 \\
\hline & 3 & 步距 $15 \mathrm{~cm}$, 平距对中后偏移 $2 \mathrm{~cm}$ & 17.6 & 0.4 \\
\hline & 4 & 步距 $20 \mathrm{~cm}$, 平距对中后偏移 $2 \mathrm{~cm}$ & 17.6 & 0.4 \\
\hline & 5 & 步距 $30 \mathrm{~cm}$, 平距对中后偏移 $2 \mathrm{~cm}$ & 16.2 & -1.0 \\
\hline & 6 & 步距 $15 \mathrm{~cm}$, 远处对中, 距离中心点 $10 \mathrm{~cm}$ & 17.6 & 0.4 \\
\hline \multirow{3}{*}{ 曲线段 } & 1 & 步距 $20 \mathrm{~cm}$, 左侧管片平距对中 & 39.6 & / \\
\hline & 2 & 步距 $20 \mathrm{~cm}$, 右侧管片平距对中 & 39.6 & 0.0 \\
\hline & 3 & 步距 $20 \mathrm{~cm}$, 左侧管片平距对中, 扫描断面向前平移 $30 \mathrm{~cm}$ & 39.6 & 0.0 \\
\hline
\end{tabular}

从以上结果可以看出, 在直线段平距对中与远处对中结果相差不大, 全站仪步距不同、照准位置小范围偏移对结果影响也不大, 在曲线段按照 平距对中, 扫描断面平移对结果基本无影响。

4. 2 根据上述方法, 选取某段隧道中一环进行了不同人为误差因素下 的断面几何尺寸误差结果比对试验, 试验共进行了 11 个工况, 详细结果如 下图所示:

从以上结果可以看出, 在人为误差影响下, 全站仪的架站高度、全站仪 架设位置左右前后偏移都对测量结果影响不大, 但是全站仪测量的照准视 线与管片的不垂直对结果影响较大, 偏移越多, 偏差越大。

综合上述两个实验, 可以看出上述断面、点位的的选取方法在应用过 程中取得了很好的效果, 能很好的减小全站仪断面测量过程中的误差。

\begin{tabular}{|c|c|c|c|}
\hline $\begin{array}{c}\text { 工 } \\
\text { 况 }\end{array}$ & 详情 & $\begin{array}{c}\text { 最大径长变 } \\
\text { 化量 }(\mathrm{mm})\end{array}$ & $\begin{array}{c}\text { 与工况 } 1 \\
\text { 差值 }(\mathrm{mm})\end{array}$ \\
\hline 1 & 架站到轨道中心点, 量全站仪高度, 对中后测量 & 34.8 & $/$ \\
\hline 2 & 架站到轨道中心点, 对中后转动 $5 \mathrm{~cm}$ 测量 & 40.8 & 6.0 \\
\hline 3 & 架站到轨道中心点, 对中后转动 $10 \mathrm{~cm}$ 测量 & 45.2 & 10.4 \\
\hline 4 & 架站到轨道中心点, 对中后转动 $15 \mathrm{~cm}$ 测量 & 56.4 & 21.6 \\
\hline 5 & 架站到轨道中心点, 对中后转动 $20 \mathrm{~cm}$ 测量 & 68.0 & 33.2 \\
\hline 6 & 架站靠近左侧轨道偏离中心 $30 \mathrm{~cm}$, 量全站仪高度与工况1一致 & 36.6 & 1.8 \\
\hline 7 & 架站靠近右侧轨道偏离中心 $30 \mathrm{~cm}$, 量全站仪高度与工况1一致 & 35.2 & 0.4 \\
\hline 8 & 架站向前移动 $30 \mathrm{~cm}$, 量全站仪高度与工况1一致 & 36.8 & 2.0 \\
\hline 9 & 架站向后移动 $30 \mathrm{~cm}$, 量全站仪高度与工况1一致 & 35.6 & 0.8 \\
\hline 10 & 架站高度降低 $20 \mathrm{~cm}$, 对中后测量 & 36.0 & 1.2 \\
\hline 11 & 架站高度升高 $20 \mathrm{~cm}$, 对中后测量 & 36.4 & 1.6 \\
\hline
\end{tabular}

\section{5 结束语}

全站仪在实际应用于隧道断面测量过程中, 在不同单位或人测量时, 前后测量结果可能存在较大的误差, 这就需要采用统一合理的测量方法, 特别是在断面、点位的选取上需要统一规范。通过原因分析, 我们在断面、 点位选取上做了统一之后, 很好的避免人为误差对断面测量的影响, 保证 断面测量数据的准确性, 为后续施工过程中数据分析提供了可靠的依据, 也为后续仪器使用过程中遇到问题后提供了一个新的思路。

\section{[参考文献]}

[1]高益健.利用徕卡全站仪机载程序进行隧道断面测量.测绘工 程,2014,11(34):71-73.

[2]白文波,赵勇.圆形隧道基于全站仪断面测量数据的椭圆拟合方法 [C]长三角论坛——测绘分论坛,2007,(11):30-32.

[3]费先明.基于全站仪的地铁隧道断面测量及数据处理.城市勘 测,2017,8(04):134-137. 